\title{
EDITORIAL
}

\section{The next generation}

\author{
A better understanding of the factors that affect children's desire to follow a career in \\ science is vital if we are to inspire the next generation of scientists.
}

Do you remember when you decided that you wanted to be a scientist and what factors influenced your choice? Perhaps you had a family member who was a scientist or had an interest in science. Maybe you had an inspirational science teacher at school who encouraged you. Or was it an inherent interest in science that spurred you on to take it up later in life?

The way that children in the United Kingdom view science, and science careers, was the subject of a recent report from a research programme based at King's College London. The ASPIRES (Science Aspirations and Career Choice: Age 10-14) project is an ongoing 5-year study investigating the factors that influence children's attitudes to science and their educational choices. Funded by the UK Economic and Social Research Council as part of their Targeted Initiative on Science and Mathematics Education, the report (Ten Science Facts and Fictions) reveals that, although as they finish primary school (aged 10-11 years) the majority of children enjoy science, view scientists in a positive light and have parents who think science is important, less than $20 \%$ are interested in actually pursuing a career in science. Of course, ' $80 \%$ of children not interested in a science career' makes a good headline, but if this turned out to be true - that is, if $20 \%$ of children went on to have a science-related career then that would in fact be of great benefit to the science and technology sectors. The more interesting point is the fact that, perhaps by virtue of their natural curiosity, the majority of children aged 10-11 years have a great interest in science and the world around them, but as they start secondary school there is already a massive disconnect between this interest and the idea of being a scientist. Related to this, the report also reveals that there is a widely held perception among children and parents that the range of science-related careers available is limited. Combined with previous research indicating that when children start secondary school their interest in science often begins to wane, this report highlights the need to integrate an awareness of STEM (science, technology, engineering and medicine)-related careers into the curriculum at Key Stage 3 (aged 10-14 years), if not earlier, emphasising science as a multifaceted career option that is available to all, regardless of ethnicity, gender or social background.

Similar results have been obtained from a different project that is targeted at an older age group. The ROSE
(Relevance of Science Education) international research project involves 40 countries and aims to identify the factors that influence the attitudes of 15 -year-olds to science and technology and their motivation to learn. This study has found that in their day-to-day lives teenagers can be interested in science, but this does not translate into an interest in a formal setting such as school. In this age group, although there is widespread agreement that science and technology are important for society, there is little interest in science as a career, and there is a clear difference in gender with regard to specific career options, with much less interest from girls than from boys for careers that have a technical or mechanical focus.

Science education is obviously an area of concern for all scientists. The UK Royal Society recently announced a major project aimed at producing a vision for science and maths education from ages 5 to 19 to "help ensure the UK has a scientifically and mathematically literate population", and a call for views is now open. Interestingly, however, among the "galaxy of stars" who constitute the 16-member project committee, there are only three representatives who currently work in schools, as head teachers. The Society must ensure that the views of the science and maths teachers who engage with students on a daily basis are adequately represented.

At an individual level, what can you do? As microbiologists, it is always possible to get more involved in sharing your passion for science and promoting microbiology as a career. In the United Kingdom, the Society for General Microbiology (SGM) is leading the way with an excellent range of specially developed educational materials that can be used in outreach programmes or public events and are available free to SGM members. Many other learned societies worldwide also provide educational materials. So, the next time you are asked to participate in an outreach visit to a school or a science fair, why not volunteer? After all, where would we be without the next generation?

\section{FURTHER INFORMATION}

ASPIRES: http://www.kcl.ac.uk/sspp/departments/education/research/ aspires/index.aspx

ROSE: http://roseproject.no.

Royal Society Vision: http://royalsociety.org/education/policy/vision/ SGM's educational materials: http://www.microbiologyonline.org.uk Ten Science Facts and Fictions: http://www.kcl.ac.uk/sspp/departments/ education/research/aspires/10FactsandFictionsfinalversion.pdf ALL LINKS ARE ACTIVE IN THE ONLINE PDF 